Article

\title{
Assessment of Flood Risk Exposure for the Foshan-Zhongshan Region in Guangdong Province, China
}

\author{
Qi Zhang ${ }^{1}$, Wei Jian ${ }^{2}$ (I) and Edmond Yat Man Lo ${ }^{1, *}$ \\ 1 School of Civil and Environmental Engineering, Nanyang Technological University, 50 Nanyang Avenue, \\ Singapore 639798, Singapore \\ 2 Institute of Catastrophe Risk Management, Nanyang Technological University, 50 Nanyang Avenue, \\ Singapore 639798, Singapore \\ * Correspondence: cymlo@ntu.edu.sg
}

Received: 21 March 2020; Accepted: 15 April 2020; Published: 18 April 2020

\begin{abstract}
Floods have caused $20 \%$ of the worldwide economic losses resulting from catastrophe events over 2008 to 2018. In China, the annual flood economic losses have exceeded CNY 100 billion from 1990 to 2010, which is equivalent to 1\% to 3\% of China's Gross Domestic Product (GDP). This paper presents a rainfall-runoff model coupled with an inundation estimation to assess the flood risk for a basin within the Foshan-Zhongshan area of the Pearl River Delta (PRD) region in China. A Hydrologic Engineering Center's Hydrologic Modeling System (HEC-HMS) model was constructed for the crisscrossing river network in the study basin where the West and North Rivers meet, using publicly accessible meteorological, hydrological and topographical datasets. The developed model was used to analyze two recent flood events, that in July 2017 with large upstream river inflows, and in June 2018 with high local rainfall. Results were further used to develop the needed river rating curves within the basin. Two synthetic events that consider more severe meteorological and hydrological conditions were also analyzed. These results demonstrate the capability of the proposed model for quick assessment of potential flood inundation and the GDP exposure at risk within the economically important PRD region.
\end{abstract}

Keywords: urban flooding; HEC-HMS; Pearl River Delta (PRD), flood risk assessment; inundation estimation; rating curves

\section{Introduction}

Rivers and waterways have long been attractive locations for human settlements since the first civilizations, owing to the supply of resources and easy transportations. Most of the cities today have rivers or lakes crossing their urban landscape, providing comfort and ecological diversity for urban citizens but at the same time, posing a range of challenges in light of the potential risk from extreme weather events. In China, large rivers such as the Yangtze River, the Yellow River and the Pearl River, are home to many major cities, even mega cities, along their main channels and tributaries in the wider catchments. As such, flooding has been a long-standing hazard over the centuries which often causes more widespread economic losses when compared with other natural perils in China [1]. Moreover, most of the flood losses are not covered by flood insurance in China. Based on the NatCatSERVICE database by Munich Re, the total flood loss in China in 2016 was USD $\$ 111$ billion, only $2 \%$ of which was recoverable [2]. The low public awareness of the potential flood risk, including that of insurance products, together with a lack of rapid flood risk assessment tools, hinders the effort to develop and promote more appropriate flood insurance protection. 
Evaluation of flood risk is often carried out for economic exposures, such as physical assets and Gross Domestic Product (GDP) - the former relates to direct losses while the latter is an indicator of the indirect impact. Calculation of direct losses, particularly at a micro-level, requires a detailed building inventory including information on building use, footprint and height, as captured in a Geographic Information System (GIS) with known (or predicted) flood extent and depth overlaid [3-5]. However, this requires a major effort in data collection or access to building inventory databases, as existing at local authorities, both of which are frequently not feasible. Thus, evaluation of flood risk is often done at a macro-level, particularly for larger areas (e.g., regional-level and larger) and uses proxies such as GDP and/or general building stock information as measures of the potential impact on the overall economic output and asset values. A number of recent studies at the national and global scales have used GDP as the main socioeconomic exposure for natural hazard risk evaluation [6-8]. As GDP is a widely reported economic indicator, evaluating the GDP at risk can provide a holistic view that reflects both the direct and indirect losses as arising from the wider impact of economic and societal disruptions.

The main causes of flood events in China are due to extreme rainfall events, modification of river channels from urbanization and sediment transport, and poor protection measures. The Intergovernmental Panel on Climate Change (IPCC) has highlighted the increasing climate change related risk for urban areas from extreme precipitation, rising sea levels, and inland and coastal flooding in their Fifth Assessment Report [9]. Thus, it is crucial to better manage rivers and their interaction with floodplains and urban landscape for safeguarding the populations, living environment, and economy of urban communities near major rivers.

Flood risk assessment relies on a good representation of the underlying rainfall-runoff processes through hydrological and hydrodynamic models to estimate the potential adverse consequences from user-specified meteorological and hydrological conditions. Hydrological models are often used to describe the rainfall-runoff and river-floodplain interaction. Zhao et al. developed the Xinanjiang model, a representative lump hydrological model, for applications in China [10-12]. With the advent of computer power, satellite imagery and remote sensing, more physically distributed hydrological models coupled with gage/telemetered data within GIS are used. Some of the more recent reported modeling works for basins in China have utilized the Soil Water Assessment Tool (SWAT) for soil erosion, sediment transport and water quality studies [13-15], semi-distributed Topographic hydrologic model (TOPMODEL) for floodplain inundation assessment [16,17] and Hydrologic Engineering Center's Hydrologic Modeling System (HEC-HMS) for storm-runoff and flood evaluation [18,19]. The main limitations of using these models, however, are that the datasets required for an accurate representation of the river channel geometries are often lacking, and also the constraints of computational effort for modeling a large and complex basin. Field measurements of river cross-sections are often scarce, such datasets are generally not updated regularly and open access is not available to the research field. Observation datasets from gaged basins such as precipitation, flowrate and water stages, may be more accessible but the temporal coverage varies depending on the data made available. Thus, a more robust model that can capture the key dynamics of the regional rainfall-runoff-inundation process despite lacking certain datasets is desirable for practical purposes.

This paper presents a rainfall-runoff model based on the HEC-HMS model coupled with an empirical inundation estimation using only limited publicly accessible data for flood hazard assessment of a basin in the Foshan-Zhongshan area of the Pearl River Delta (PRD) region in China. The economically vital PRD region is located in the deltaic floodplain of the Pearl River Basin where the complex Pearl River network meets the South China Sea. Owing to the interaction between river and tidal dynamics, this low-lying area has frequently experienced major flood losses in its long history. The HEC-HMS model has been chosen for this study as it is open source, widely tested and accepted by the engineering community for hydrologic analysis. Several recent studies have applied the HEC-HMS model for flood assessment in various catchments in China with satisfactory results [20-22]. The proposed model is used to determine the rainfall runoff from two recent flood events with the HEC-HMS-modelled discharges benchmarked with observations. The first event occurred in July 2017, and was a typically 
large upstream river inflow event with relatively low local rainfall, while the second event occurred in June 2018 which represents a high local rainfall-induced flooding event but much lower upstream inflow. Two more severe scenarios, with the large inflow coinciding with high local rainfall, and rainfall further increased due to climate change, are also modelled. Given that the majority of the population and assets in the PRD region concentrates in the low-lying areas below $0.5 \mathrm{~m}$ relative to the mean sea level, the region is most susceptible to impacts from climate change. The potential inundated area, as well as GDP exposure subjected to potential flood hazard over these scenarios at risk, are assessed.

\section{Materials and Methods}

\subsection{Study Area}

The PRD region lies between latitude $22^{\circ} \mathrm{N}$ to $25^{\circ} \mathrm{N}$, and longitude $112^{\circ} \mathrm{E}$ to $115^{\circ} \mathrm{E}$ in southern China. It consists of nine cities, which are Guangzhou, Shenzhen, Dongguan, Zhuhai, Foshan, Zhongshan, Jiangmen, Zhaoqing and Huizhou from Guangdong province, and two Special Administrative Regions (SARs) of Hong Kong and Macau. The PRD region contributed to 13\% of China's GDP in 2017 and has an enormous concentration of population and socio-economic exposures [23].

The rainy season for the PRD region is between April and September, during which $80 \%$ of the annual total rainfall occurs. The weather system is affected by the rainy (locally known as "Meiyu") season between April and June, and the typhoon season over July to September when tropical cyclones may bring heavy rainfall and/or storm surges. The river network running through the PRD region consists of three major rivers, the West River (Xijiang), the North River (Beijiang) and the East River (Dongjiang), respectively. The crisscrossing water network in the PRD region encompasses a drainage area of $26,800 \mathrm{~km}^{2}$, accounting for $5.9 \%$ of the entire Pearl River Basin.

Our study area is located in the floodplain downstream of the Makou and Sanshui stations along the West and North Rivers (Figure 1). The boundary of the study area is determined by the sub-basin delineation of the area surrounding the main network of the West and North Rivers. This area is of great interest for flood risk exposure study as the West and North River networks have a long history of riverine flood loss events occurring yearly. It is also home to a number of major cities and urban districts in the PRD region which includes Foshan, Zhongshan and smaller parts of several other PRD cities such as Zhuhai, Jiangmen, Guangzhou, and Zhaoqing (Figure 1c). The study area has a total drainage area of $6682 \mathrm{~km}^{2}$, which represents 1.6\% of the total Pearl River Basin drainage area and 12\% of the PRD area.

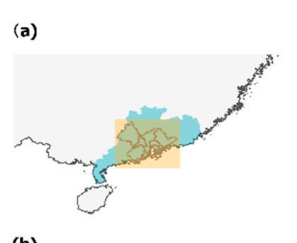

(b)
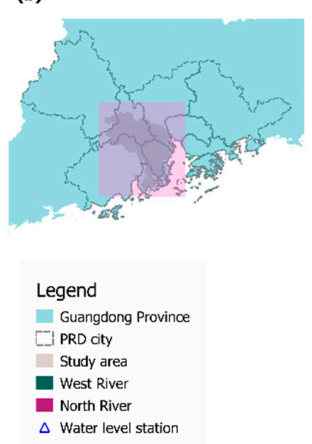

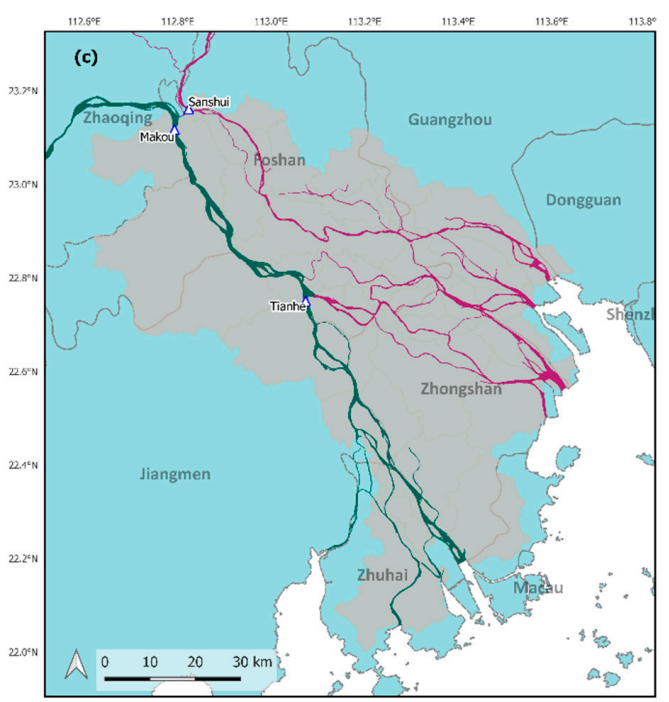

Figure 1. Location of the study area. (a) Southern part of China, (b) Guangdong province and Pearl River Delta (PRD) cities, and (c) study area (shaded in grey) as located primarily in the Foshan-Zhongshan region around the West and North Rivers. The rivers enter into the study area via the Makou and Sanshui gage stations. 


\subsection{Data}

\subsubsection{Meteorological and Hydrological Data}

Hourly rainfall and river stage data (both locations and warning levels) were downloaded from the Guangdong Province Command Center for Flood, Drought and Typhoon Emergencies (http://www.gd3f.gov.cn:9001/Report/) for the two historical events in July 2017 and June 2018, respectively. There are 25 rainfall gage stations and 10 river gage stations used in total (Figure 2a), of which seven stations have both rainfall and water level data. One of the stations, Tianhe station (a downstream station on the West River), has only daily water level (measured at 8:00 am each day) available. This station was later used to benchmark the parameters used in the HEC-HMS model. Table 1 details the river discharge data collected from various sources for the Makou and Sanshui stations at the upstream part of the study area, and the Tianhe station along the West River. Some additional limited discharge data was also gathered from newspapers and local reports for qualitative benchmarking.

Table 1. River discharge data used.

\begin{tabular}{cccc}
\hline Data Source & Stations & Resolution & Duration \\
\hline $\begin{array}{c}\text { Hydrological Bureau of Guangdong } \\
\text { Province-Foshan Municipal } \\
\text { Administration }\end{array}$ & Makou, Sanshui & Hourly discharge & 7-10 June 2018 \\
(http://www.gdsw.gov.cn/fsfj.html) & & & \\
\hline $\begin{array}{c}\text { Pearl River Hydrological Bureau of Water } \\
\text { Resources Committee of Pearl River, } \\
\text { Ministry of Water Resources (http: }\end{array}$ & Makou, Sanshui & $\begin{array}{c}\text { Daily discharge } \\
\text { (at 8:00 am) }\end{array}$ & July 2017, \\
//www.Zwsw.gov.cn/syqxx/index.shtml) & & June 2018 \\
\hline $\begin{array}{c}\text { Pearl River Navigation Administration, } \\
\text { Ministry of Transport (www.zjhw.gov.cn) }\end{array}$ & $\begin{array}{c}\text { Makou, Sanshui, } \\
\text { Tianhe }\end{array}$ & $\begin{array}{c}\text { Daily discharge and } \\
\text { water level } \\
\text { (at 8:00 am) }\end{array}$ & $\begin{array}{c}\text { June-August } \\
\text { 2014-2017, }\end{array}$ \\
\hline
\end{tabular}

\subsubsection{Topographical, Land Use and Land Cover Data}

The one arc-second (spatial resolution of $30 \mathrm{~m}$ ) NASA Shuttle Radar Topography Mission (SRTM) elevation dataset (https://www2.jpl.nasa.gov/srtm/) was used as the digital elevation model (DEM) in this study. We further have the major rivers burned into the DEM to facilitate basin delineation. The Global Land Cover-SHARE (GLC-SHARE) database (http://www.fao.org/geospatial/ resources/detail/en/c/1036591/), provided by the Land and Water Division, Food and Agriculture Organization (FAO), United Nations, was used to categorize the land cover types. The dataset has a spatial resolution of 30 arc-seconds (spatial resolution of $1 \mathrm{~km}$ ) and includes 11 land cover types. For purposes of identifying impervious land cover for surface runoff calculation, we further reclassified the artificial surface type as impervious, and the other land cover types as pervious. The 2014 dataset for Guangzhou, Guangdong, from the Atlas of Urban Expansion, Urban Expansion Program (http://www.atlasofurbanexpansion.org/) by the Marron Institute of Urban Management, New York University (NYU), was used to identify the urbanized and rural areas for disaggregation of GDP exposure in Section 2.5. Even though this dataset is named as Guangzhou, it covers a wider area than the latest administrative boundary of Guangzhou city. Most cities in our study area, such as Foshan, Zhongshan and the urban districts of Jiangmen, are also included within this dataset. This dataset has a spatial resolution of $30 \mathrm{~m}$.

\subsection{HEC-HMS Model}

Figure $2 \mathrm{~b}$ shows the developed HEC-HMS model for the study area. It consists of 28 sub-basins delineated using the SRTM DEM data. For each sub-basin, the received rainfall is calculated based on 
an area-weighted average using Thiessen polygons. Through proximity and neighborhood analysis, a Thiessen polygon is constructed for each gage station, and collectively they encompassed the entire study area. The Soil Conservation Service (SCS) curve number (CN) method is used in the loss model for calculating infiltration, which is then subtracted from rainfall before simulating the surface runoff. It assumes a constant ratio between the initial loss and the potential maximum retention of the ground, as further determined through a CN number based on the land cover and hydrologic soil type. The hydrologic soil types are classified based on the minimum infiltration rate after prolonged wetting, such as that occurring in this study, which then gives a slight over-estimation of the precipitation excess during the initial part of the event. Two CN numbers were selected following the HEC-HMS technical manual [24,25] based on the land cover and soil type, CN number 98 for impervious land and 60 for pervious land. The percentage of impervious land cover is calculated based on the artificial surface type in the GLC-SHARE database. The recession method is assumed where the flow decreases exponentially after the rainfall event and is used to represent the baseflow. Groundwater discharge to the river via infiltration and seepage is not considered in the model given the timescale of the large rainfall events and the highly urbanized nature of the study area. We expect this contribution to be negligible within the immediate basin response timeframe of this study.

The river network developed has two source inflows at Makou and Sanshui on the West and North Rivers respectively (Figure 2a), and 8 outlets (Figure 2b). A total of 31 reach components are included, of which 12 are from the North River and 19 are from the West River. The Muskingum-Cunge Routing method is used to simulate the propagation or attenuation of river flow within the individual reach segment. As the two main rivers at the upstream of the study area branch into several tributaries downstream, the split ratios become one of the key factors for model calibration. The split ratios for 2 of 11 diversions in the HEC-HMS model are based on the reported ratios at Ganzhu and Zidong stations [26], while the rest are determined by width ratios between the diverted reaches. River cross-sections are assumed to be trapezoidal as commonly used in lieu of detailed information on river geometry. An average Manning's n of 0.023 is generally recommended and is used here, this is based on a literature review for the PRD region [27-29] with reported values ranging over 0.014-0.03. The average slopes of the West and North Rivers are $0.045 \%$ and $0.0053 \%$ [30] respectively, and these are used as slopes for reaches in the model.

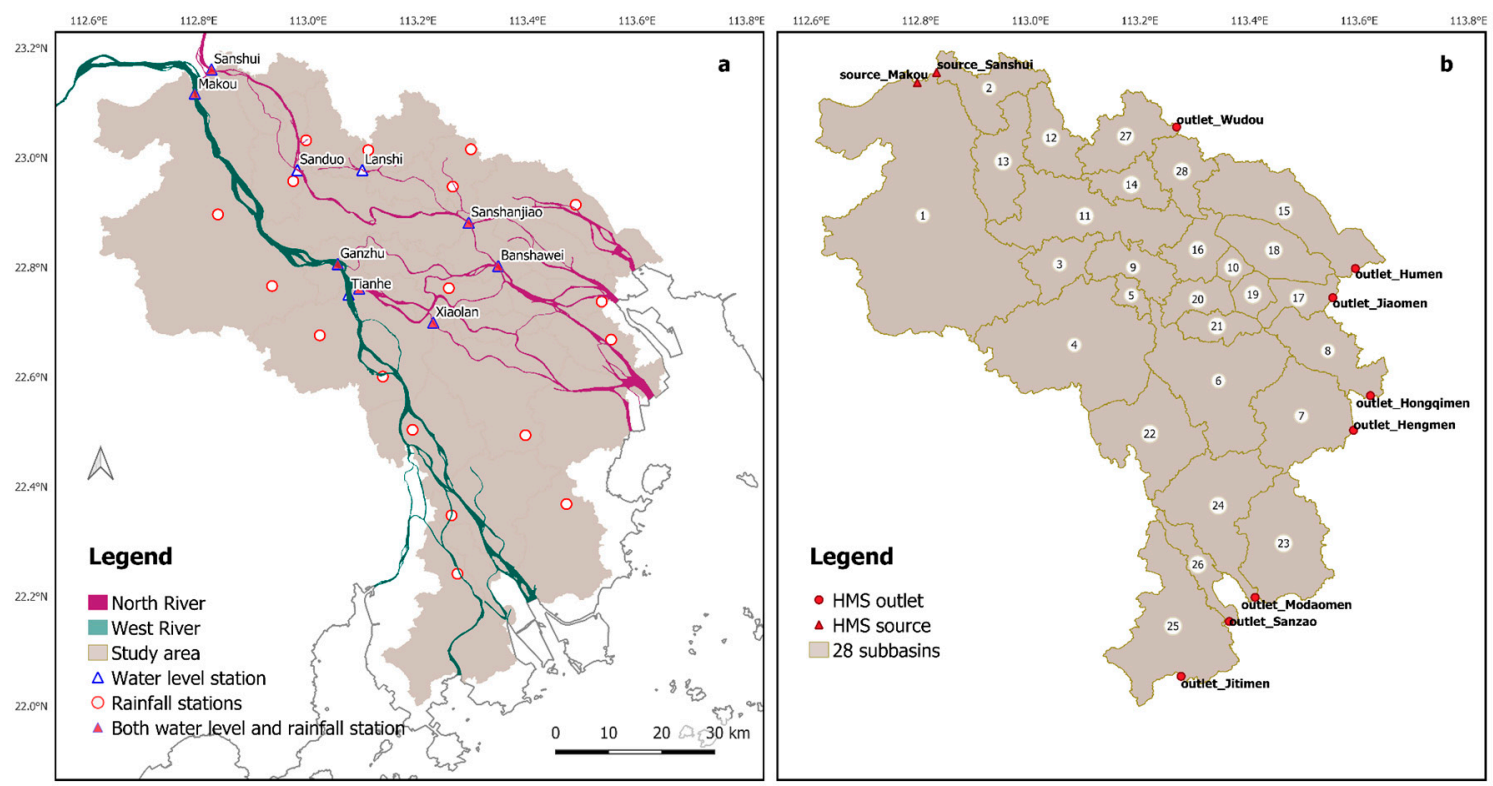

Figure 2. (a) Location of key rainfall, river discharge and water level gage stations, and (b) Hydrologic Engineering Center's Hydrologic Modeling System (HEC-HMS) model configuration which details the 28 sub-basins in the HEC-HMS's basin model with two sources and eight outlets. 


\subsection{Estimation of the Inundation Extent}

The floodplain inundation is calculated when the simulated discharge from the HEC-HMS model exceeds the river bankfull depth, with the overflow to the surrounding floodplain being treated as a volume-filling process based on mass conservation. The potential inundation extent and the corresponding flood depth are estimated based on the river stage (level) relative to the warning level via a side-weir discharge process. This approach was taken due to a lack of detailed floodplain information needed in detailed hydraulic and inundation modeling. The warning levels published for key river stations are assumed to be that at the bankfull level. Through rating curves derived from the HEC-HMS results, the river bankfull discharge $\left(Q_{B F}\right)$ is first calculated using the warning level at the respective stations. The overbank flow situation is then modelled as an open-channel side-weir discharge, with the embankment crest parallel to the open-channel flow direction. Hence, when the river water level exceeds the bankfull (or warning level), it drains through the side discharge and continues until the water level falls below the bankfull level.

The flowrate $Q(x)$ along a channel with a double-sided weir opening can be described as [31]:

$$
\frac{d Q}{d x}=-\frac{4}{3} C_{m} \sqrt{2 g}(h-w)^{1.5}
$$

where $d x$ is the incremental distance along the weir, $C_{m}$ is the known weir discharge coefficient but doubled from that for a single side weir, $g$ is the gravitational acceleration, $h(x)$ is the instantaneous water level, and $w$ is the fixed level of the side weir (i.e., the warning level). Assuming a solution for $Q(x)$ in the form of a rating curve as:

$$
Q(x)=C_{1} h(x)+C_{2}
$$

where $C_{1}$ and $C_{2}$ are known constants of the rating curve, Equation (1) can be written as:

$$
\frac{d Q}{d x}=-\frac{4}{3} C_{m} \sqrt{2 g}\left(\frac{Q}{C_{1}}-\left(\frac{C_{2}}{C_{1}}+w\right)\right)^{1.5}
$$

Equation (3) for $Q(x)$ can then be integrated and solved for the length $(L)$ of side weir over which the overbank side discharge occurs. The solution has the form:

$$
L=\sqrt{\frac{9 C_{1}^{3}}{8 C_{m}^{2} g\left(Q_{2}-Q_{B F}\right)}}-\sqrt{\frac{9 C_{1}^{3}}{8 C_{m}^{2} g\left(Q_{1}-Q_{B F}\right)}}
$$

where $Q_{1}$ is the discharge at the start of the side weir $(x=0)$ and with $Q_{1}$ given by the HEC-HMS being greater than $Q_{B F} . Q_{2}$ is the discharge at the end of the weir at $x=L$, which theoretically should be $Q_{B F}$ but this implies an infinite $L$ from the form of the solution in Equation (4). Thus, for our calculation, two approaches for determining $L$ were evaluated by assuming $Q_{2}=0.99 Q_{B F}$ or $\left(Q_{1}-Q_{2}\right)=0.9\left(Q_{1}-Q_{B F}\right)$. As both approaches gave similar estimates for $L$, an averaged $L$ is then taken as the final result. Lastly the weir coefficient, $C_{m}$, is taken as $0.24+0.54\left(w L / h_{1}\right)$, where $h_{1}$ is the water level corresponding to $Q_{1}$ [32].

The total volume of overflow is then readily calculated as the summation of the excess discharge, $\left(Q_{1}-Q_{B F}\right)$, over the time period when $Q_{1}>Q_{B F}$. It is further assumed that the overflowed water flows into the nearest and lowest elevation areas first before inundating areas of higher elevation. A potential inundation circular (PIC) area is defined as a circular region with its center located at the station where overflow occurs and with the inundation areas enclosed. The initial radius of the PIC is set as the side-weir length $L$, which is then gradually increased until the flood depth at the periphery of the PIC is less than $0.3 \mathrm{~m}$. In practical terms, it is assumed that only a flood depth larger than $0.3 \mathrm{~m}$ is of 
concern as local drainage and protection would likely cater for a depth of less than $0.3 \mathrm{~m}$. The flooded area and flood depth within the PIC are then determined so as to conserve the overflow volume.

\subsection{Evaluation of the GDP Exposure from Inundation}

The annual GDP data at county-level and city-level covering the study area has been collected from the Guangdong Statistical Yearbooks Database (GSYD, http://stats.gd.gov.cn/) for 2015-2017. This is further disaggregated based on the three main macro-economic sectors (primary, secondary and tertiary sectors) using the land use data as a proxy following [8,33]. Figure 3a shows the land categories of the study area based on the 2014 dataset from the Atlas of Urban Expansion, NYU. A total of seven land cover types are shown. We assume that the GDP contribution from the secondary and tertiary sectors, which generally covers manufacturing and services sectors, comes primarily from assets located in the urbanized land, i.e., comprising urban and suburban built-up areas, and urbanized open space. Correspondingly, the GDP contribution from the primary sector (mainly agricultural) is distributed to the rural built-up area, and the rural and other open space. Table 2 details the averaged GDP contributions from the primary sector (denoted as GDP_primary) and secondary and tertiary sectors combined (denoted as GDP_non-primary) as calculated from GDP statistics reported between 2015 and 2017 for counties and cities within the study area. Also, since Zhuhai city is not included in the Atlas of Urban Expansion, we use a uniform GDP density per county for the areas which are outside of the dataset boundary, as shown in Figure 3a. Figure 3b presents the spatial distribution of GDP density (unit: $\mathrm{CNY} / \mathrm{km}^{2}$ ) of the study area based on the 2017 GDP statistics. It can be seen that as a large portion of urbanized areas are located along the two river networks, a correspondingly high concentration of GDP is potentially exposed to extreme weather events.

Table 2. Primary and non-primary Gross Domestic Product (GDP) contribution ratios at county- and city-levels averaged over years 2015-2017 for the study area.

\begin{tabular}{cccc}
\hline City & County & GDP_Primary (\%) & GDP_Non-Primary (\%) \\
\hline Zhongshan & - & 1.85 & 98.15 \\
\hline Foshan & Chancheng & 0.03 & 99.97 \\
\hline & Nanhai & 1.95 & 98.05 \\
\hline & Shunde & 1.56 & 98.44 \\
\hline \multirow{2}{*}{ Jiangmen } & Gaoming & 2.36 & 97.64 \\
\hline \multirow{2}{*}{} & Sanshui & 2.99 & 97.01 \\
\hline & Heshan & 7.91 & 92.09 \\
\hline Guangzhou & Jianghai & 3.25 & 96.75 \\
\hline & Pengjiang & 1.12 & 98.88 \\
\hline
\end{tabular}

The potential GDP exposure at risk is calculated based on the flood depth and the respective GDP density of the inundated area. We assume that flooding below a depth of $0.3 \mathrm{~m}$ will not pose a significant threat to the assets and properties within the inundated area, thus no GDP exposure is at risk for depth $\leq 0.3 \mathrm{~m}$. For flood depth that exceeds $0.3 \mathrm{~m}$, the total GDP at risk is calculated as:

$$
G D P_{a t \text { risk }}=\sum \gamma_{G D P \_p r i m a r y} A_{\text {rural }}+\sum \gamma_{G D P \_n o n-p r i m a r y} A_{\text {urbanized }}
$$

where $\gamma_{G D P \_ \text {primary }}$ and $\gamma_{G D P \_n o n-p r i m a r y}$ denote the GDP density for rural and urbanized land areas of each county as based on GDP contribution from the primary sector and non-primary sectors respectively, and $A_{\text {rural }}$ and $A_{\text {urbanized }}$ are the inundated rural and urbanized areas. In the absence of 
a detailed inventory database, this GDP at risk provides a proxy for the maximum potential impact from loss of economic output as arising from damage to assets and disruption in production due to the flooding.

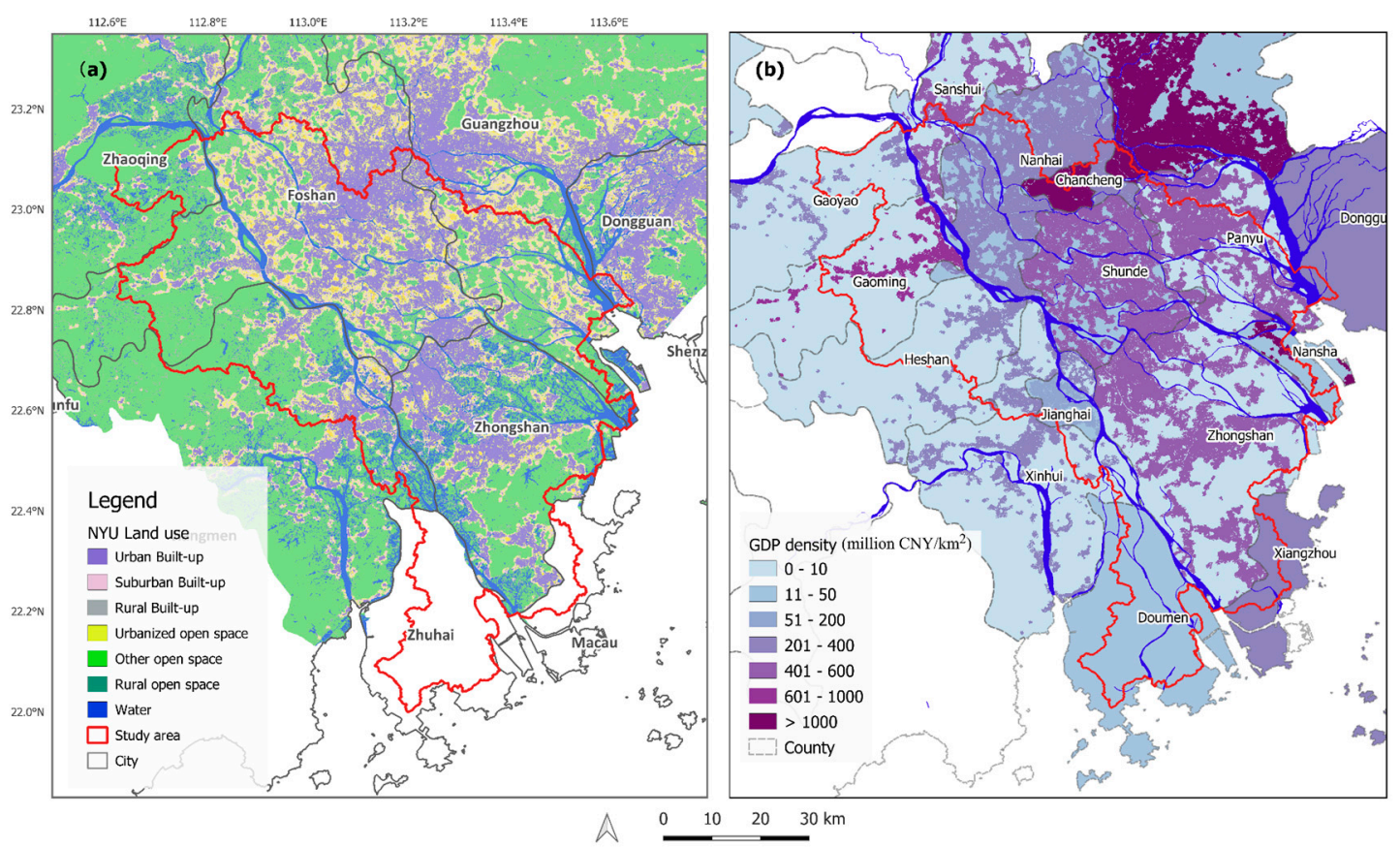

Figure 3. (a) Land categories inside the study area based on the 2014 dataset from the New York University (NYU) Urban Expansion Atlas, and (b) spatial distribution of GDP density in the study area.

\section{Results and Discussion}

\subsection{Historical Flood Events Reconstruction}

Two recent historical events were selected, as both resulted in localized flooding inside the study area. The first event occurred in July 2017, which was the first reported major flood event of the Pearl River basin during that year. The peak discharge in the West River reached close to a 20-year return period event before entering the study area. This high incoming river flow increased the water levels in the study area and resulted in localized flooding. The second event was a heavy rainfall event in June 2018, largely caused by the Typhoon Ewiniar, bringing intense rainfall to the study area whilst the incoming river stages remained below the warning level at the time of heavy downpours. Thus, the 2017 event represents a high upstream inflow but low rainfall scenario, while the 2018 event represents a low inflow but high local rainfall scenario.

\subsubsection{Meteorological and Hydrological Conditions}

The developed HEC-HMS model was used to simulate the 2017 event from 00:00 am 2 July to 23:59 pm 8 July, and the 2018 event from 00:00 am 4 June to 23:59 pm 10 June 2018. Both HEC-HMS runs have a total simulation duration of $168 \mathrm{~h}$ with a time step of $1 \mathrm{~h}$. Table 3 shows the daily accumulated rainfall averaged over the 25 input gage stations during the simulation period for both events. The peak intensity of the 2018 event falls on 8 June 2018 (Day 5 in Table 3), with the Zidong gage station reaching a maximum of $265 \mathrm{~mm}$. Figure 4 shows the isohyet maps of the peak daily rainfall from the two events, with the 2018 event clearly showing a much higher daily peak. 
Table 3. Daily rainfall (mm) averaged over 25 gage stations for the two historical events.

\begin{tabular}{cccccccc}
\hline Event & Day 1 & Day 2 & Day 3 & Day 4 & Day 5 & Day 6 & Day 7 \\
\hline 2017 Event & 16.46 & 59.52 & 45.04 & 5.58 & 7.78 & 12.45 & 16.79 \\
2018 Event & 3.76 & 13.38 & 41.28 & 86.91 & 154.39 & 0.21 & 0.02 \\
\hline
\end{tabular}

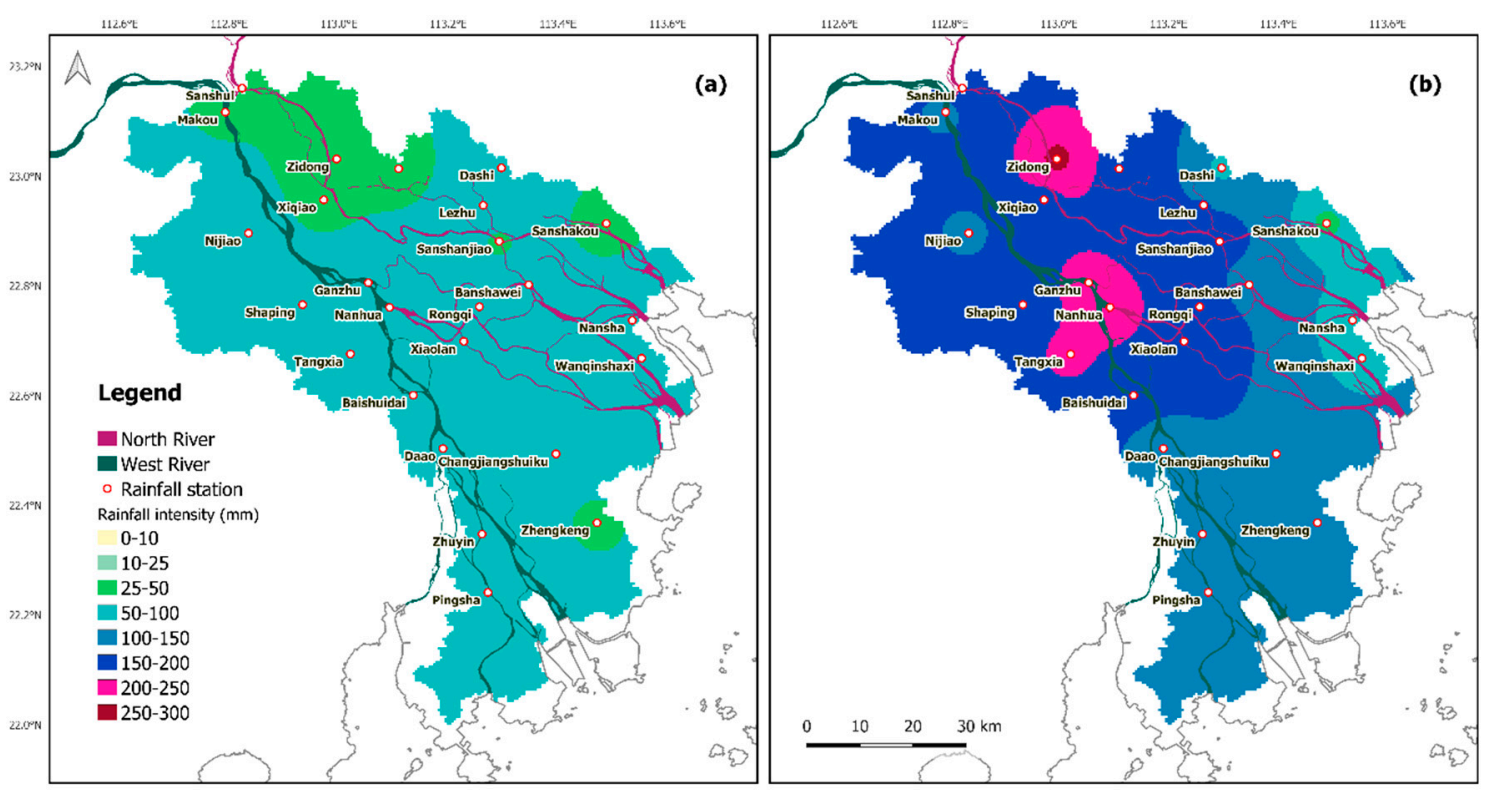

Figure 4. The maximum daily isohyet map based on the 25 rainfall gage station data occurred during the two historical events: (a) 3 July 2017, and (b) 8 June 2018. The isohyets were calculated based on the Inverse Distance Weight method.

The observed discharge and rainfall at HEC-HMS inlet stations of Makou and Sanshui are plotted in Figure 5. It is noted that the observed flowrates are much higher for the 2017 event, due to the large river inflow coming into the study basin from the Pearl River basin areas upstream. The rainfall is reported on an hourly basis, whereas the discharge is reported in a mixture of daily and hourly intervals via data from different reporting agencies (see Table 1). Given that the HEC-HMS model requires continuous inflow input at these two stations, further analysis was performed to convert the hourly reported water level at these two stations to hourly discharge. This was performed via a rating curve developed using reported data at both stations. These rating curves follow the form of Equation (2) and are developed using the reported daily discharge and water level spanning June to August of 2015 until 2017 (see Table 1, Pearl River Navigation Administration data). The developed rating curves (not shown) provided calculation of discharge values that were accurate with $R^{2}>0.9$ for the high flows. Thus, the flowrate calculated from the rating curves and reported hourly water level provides the hourly inlet source flows needed for the HEC-HMS model. The Root Mean Square Errors (RMSEs) of the rating-curve calculated flowrates are shown in Figure 5, they generally fall within 10\% of the observed flowrates at these two stations under both flow conditions. The rating-curve calculated flowrate is about $5 \%-10 \%$ higher than the daily recorded rate for both Makou and Sanshui stations for the 2017 event. For Makou station, the peak in the calculated inflow is $40,238 \mathrm{~m}^{3} / \mathrm{s}$, as based on a peak water level of $6.74 \mathrm{~m}$ at 4:00 pm, on 4 July. Both are higher than the 10-year return period flowrate of 34,600 $\mathrm{m}^{3} / \mathrm{s}$ at Makou [34]. For the 2018 event, the maximum flowrate at Makou is below $19,000 \mathrm{~m}^{3} / \mathrm{s}$, consistently below the 2017 event. Similarly, the peak flowrate at Sanshui in the 2018 event is significantly lower, barely meeting the recession flow seen in the 2017 event. 

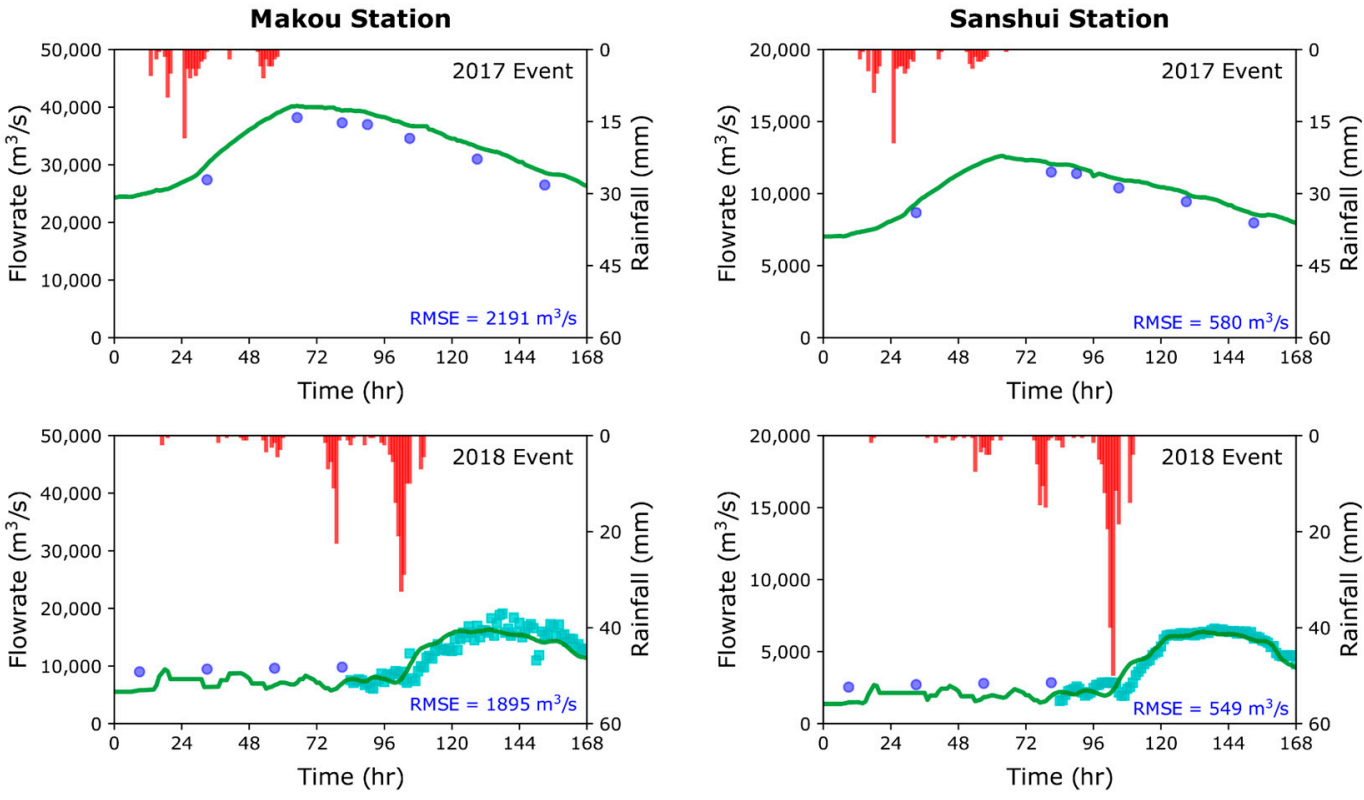

$$
\begin{array}{ll}
\text { Rainfall (observed) } \\
\hline \quad \text { Flowrate (calculated) } \\
\text { Flowrate (observed, daily) } \\
\text { Flowrate (observed, hourly) }
\end{array}
$$

Figure 5. Time series of the incoming flowrate and rainfall at the inlet stations Makou and Sanshui for 2 to 8 July 2017 (top panel) and 4 to 10 June 2018 (bottom panel). The Root Mean Square Errors (RMSEs) are calculated using the combination of both daily and hourly observed flowrate data for the 2018 event.

\subsubsection{Rating Curves}

As there is generally a lack of observed discharge data for stations inside the study basin, rating curves (i.e., river discharge to water level curves) are developed based on the HEC-HMS simulated discharge and the corresponding observed water level from these two events. These rating curves are further needed as the inundation estimation methodology described in Section 2.4 requires the water level relative to the warning level and corresponding to the HEC-HMS-simulated flowrates.

The developed rating curve results are presented in Figure 6. Linear regressions were used for Ganzhu, Xiaolan, Sanduo and Lanshi (shown in Figure 6, with station locations shown in Figure 4a) and for Nanhua and Zidong (not shown). $\mathrm{R}^{2}$ statistics are further given providing confidence of the fits. Given the magnitudes of the peak discharge from the two case study events, the developed rating curves can collectively provide for both high and low flow situations.

The daily recorded discharge at Tianhe station ranging over 3500 to $12,000 \mathrm{~m}^{3} / \mathrm{s}$ over the 2017 and 2018 events was used to benchmark the simulated discharge from the HEC-HMS model. The recorded data also allowed for a further adjustment to the assumed split ratio at Ganzhu-Tianhe-Nanhua junction (as located between Ganzhu and Tianhe stations, shown in Figure 2a) in the HEC-HMS model. The difference between the HEC-HMS discharge and daily recorded discharge are within $\pm 30 \%$ over the two events, with the exception of one recorded point for 2017 where the HEC-HMS value was 36\% higher. However, it is noted that Tianhe observed discharge and observed water level also produced a rating curve with a relatively low $\mathrm{R}^{2}$ of 0.76 for flowrates above $4000 \mathrm{~m}^{3} / \mathrm{s}$, this is in contrast to the more accurate rating curves for Makou and Sanshui. Differences in the flowrates between the recorded and rating-curve predicted at Tianhe were of $\pm 30 \%$. Thus, given the various assumptions made in the HEC-HMS model and uncertainty in the datasets used, this 30\% difference in the HEC-HMS discharge was considered satisfactory. 

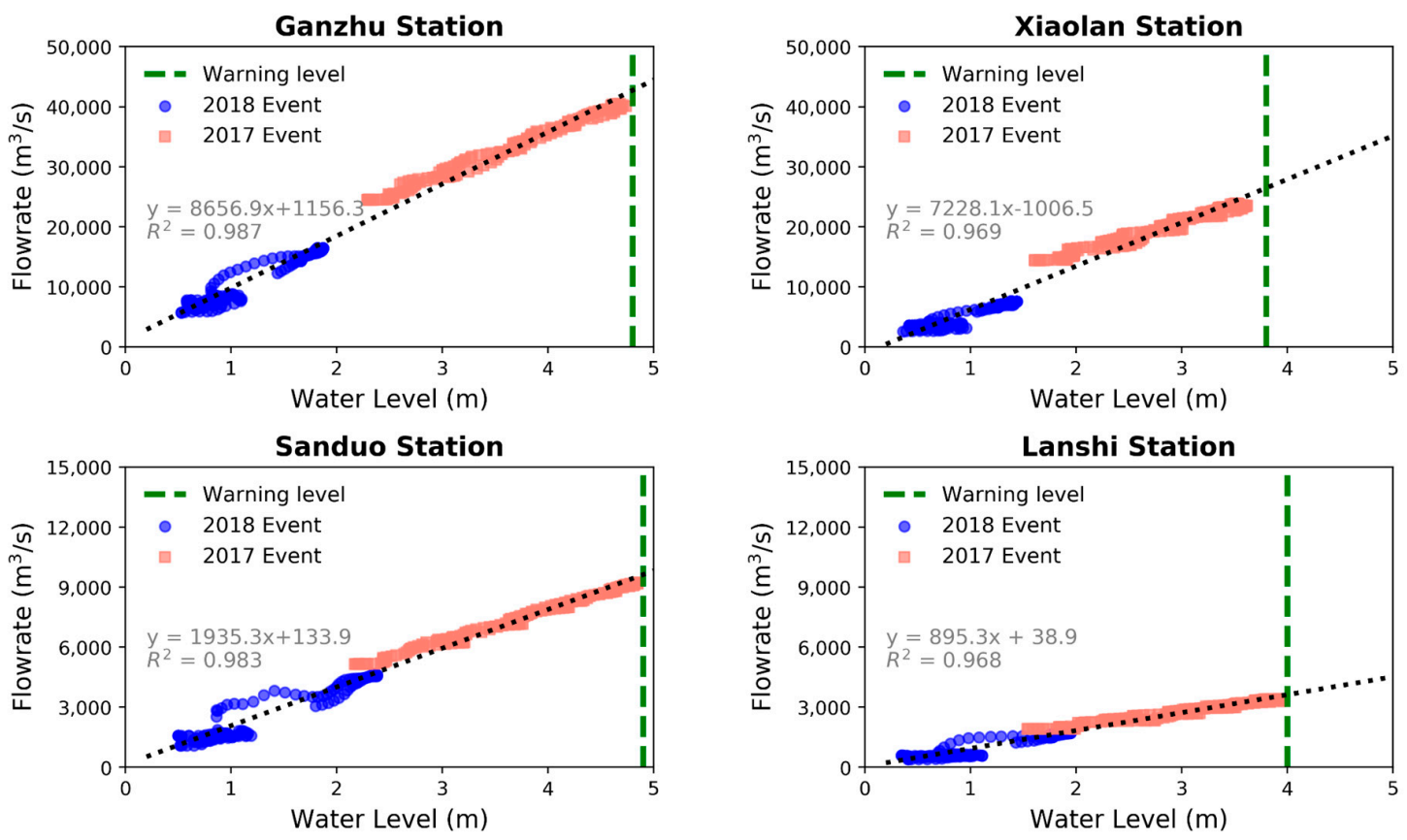

Figure 6. Rating curves for Ganzhu, Xiaolan, Sanduo and Lanshi stations along with $\mathrm{R}^{2}$ values. The flowrate is simulated using the HEC-HMS model and water level is that observed from the two historical events.

\subsubsection{HEC-HMS Model Results}

The calculated discharge from the HEC-HMS model are compared with the reported water levels at six selected stations, Ganzhu, Xiaolan, Sanduo, Lanshi, Nanhua and Zidong, with results shown in Figure 7 for Ganzhu, Sanduo and Lanshi (station locations shown in Figure 2a). The flow at these six stations are largely influenced by the upstream source flows at Makou and Sanshui, and less affected by tidal fluctuations downstream. The flowrate from the HEC-HMS model (Figure 7) is largely consistent with the variation in the observed water level. As there is more tidal influence in the 2018 event, a 12-h moving average is calculated for the observed water level so that the small tidal variations are removed from the water level changes for better comparison with the HEC-HMS results. As seen, the calculated flowrate from the HEC-HMS model varied in synchrony with the observed water level. The more pronouced discrepancy in the 2018 event is likely due to the relatively lower discharge in the river channel and hence, fluctuations from rainfall and tide effects are more readily observed.
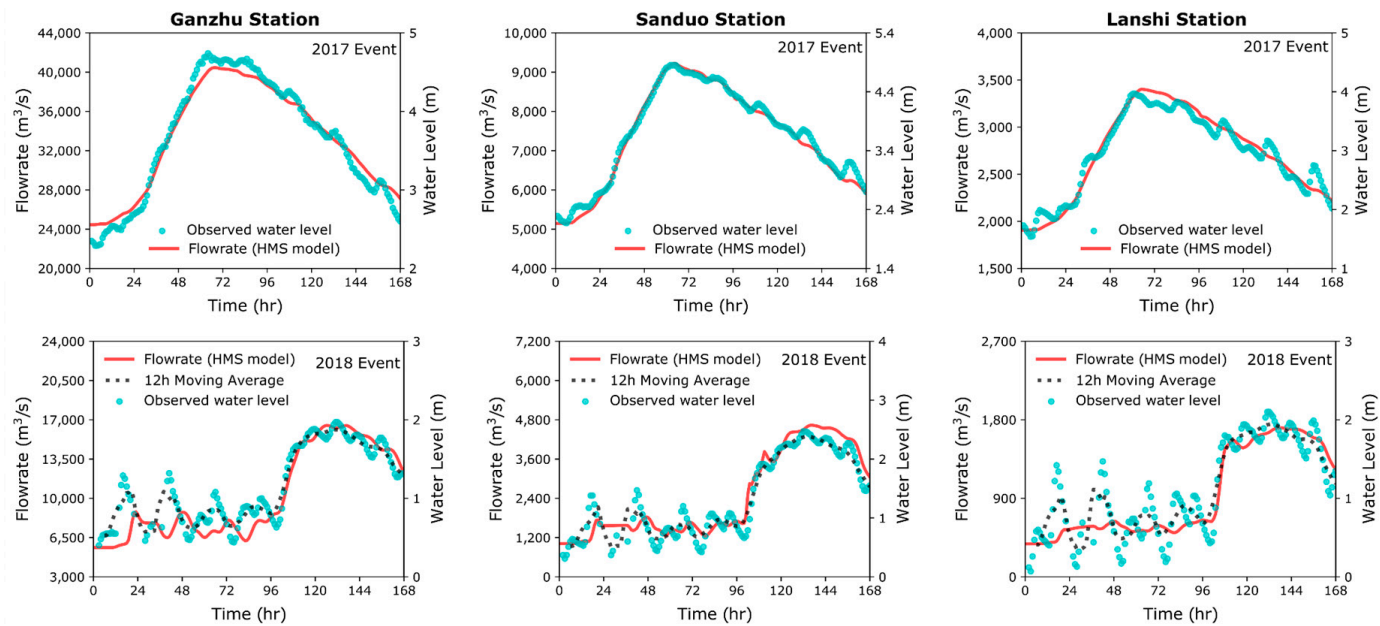

Figure 7. Comparison of the calculated discharge from the HEC-HMS model and observed water level for the two historical events: 2017 event (top panel) and 2018 event (bottom panel). 


\subsubsection{Inundation and Potential GDP Exposure at Risk}

Although none of the six gage stations were reported to have exceeded their warning levels during both events, some were very close to the warning level (e.g., at Sanduo and Lanshi), and for which inundation was reported. The reported inundation areas were mainly surrounding the Xiaolan station and the nearby waterways (Figure 8a), thus this area was selected for inundation estimation. For this, the warning level used is lowered slightly from 3.8 to $3.4 \mathrm{~m}$, so that there was a 19-h window when the water level exceeded $3.4 \mathrm{~m}$. Based on this, the total inundation area is determined to be $47,303 \mathrm{~m}^{2}$ with a flood depth of $0.3 \mathrm{~m}$ within a PIC of $7 \mathrm{~km}$ radius. This is generally consistent with observation, as summarized in Figure 8, for the reported flooding locations, PIC flood depth and inundated area, DEM ground level elevation as well as the urbanized built-up area. The total estimated urban area in the PIC is $81 \mathrm{~km}^{2}$, which accounts for $53 \%$ of the area (Figure $8 \mathrm{~d}$ ).
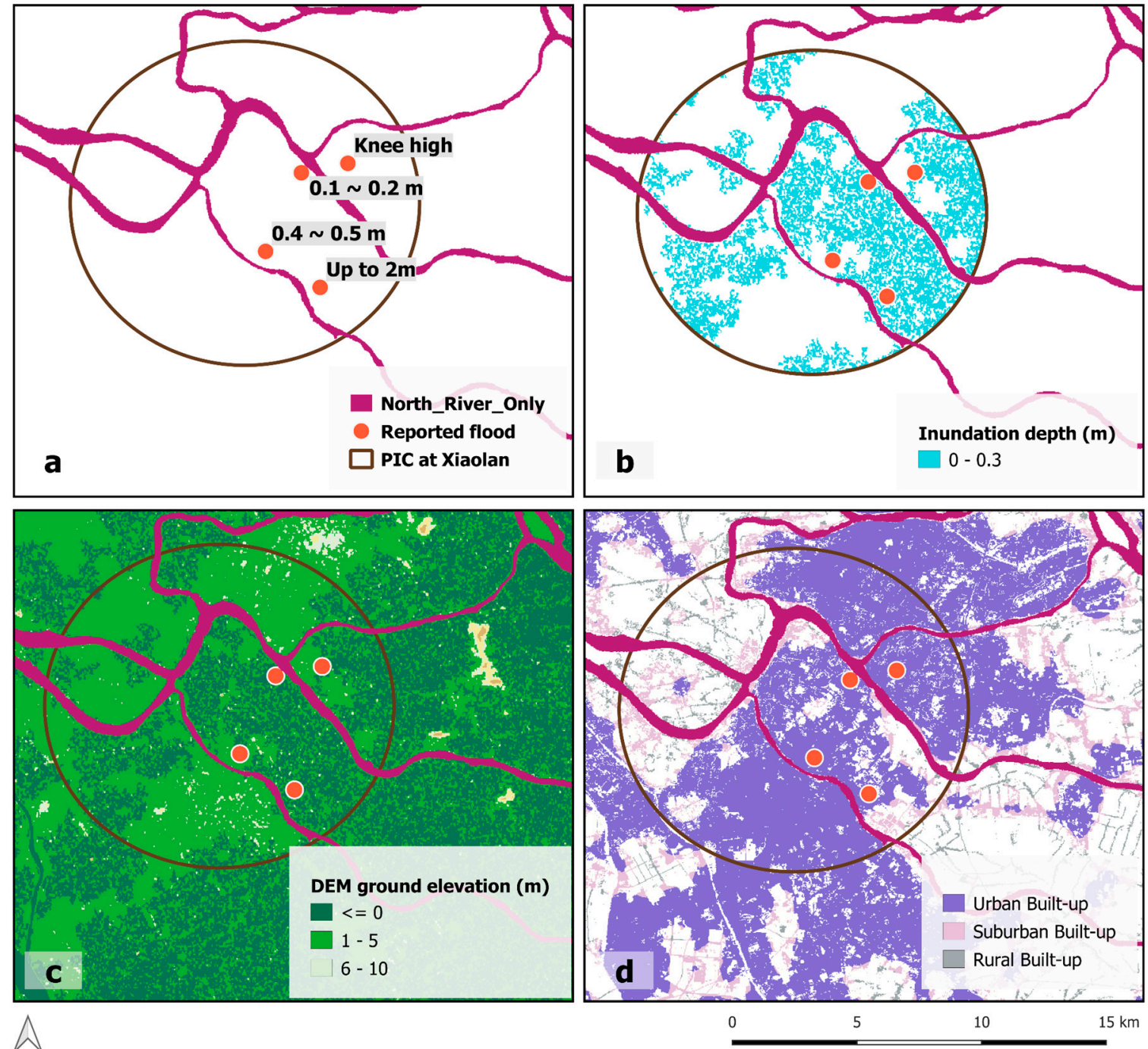

Figure 8. Comparison of the reported and estimated inundation area around Xiaolan station for the 2017 event. (a) Reported inundated areas with their corresponding flood depths [35,36], (b) calculated inundation area shown in blue shaded area within the potential inundation circular (PIC), with a radius of 7 km, (c) ground elevations from Shuttle Radar Topography Mission (SRTM) DEM, and (d) selected land categories based on the 2014 dataset from the NYU Urban Expansion Atlas.

The PIC area falls within the Zhongshan and Shunde counties, which generally have a GDP density range of 6 to 21 million $\mathrm{CNY} / \mathrm{km}^{2}$ for rural areas, and approximately 500 million CNY $/ \mathrm{km}^{2}$ 
for urban areas. As the flood depth is generally below $0.3 \mathrm{~m}$ in the PIC, we expect that the potential GDP at risk is minimal. However, it is clear that any more severe flood could pose a threat to the regional economic activities, given the high concentration of economic activities in the urban areas within this PIC.

\subsection{Synthetic Events}

Two synthetic events are further considered in this study, the first one (denoted as Syn A) combines the high river inflow of the 2017 event with the large rainfall of the 2018 event to assess the flood inundation from a potentially more severe condition. The second synthetic event (Syn B) is constructed based on the same design inputs as Syn A but with an increased rainfall, taking the climate change impact into consideration. Both synthetic events were run for $168 \mathrm{~h}$, the same as the two historical events.

\subsubsection{Design Rainfall and River Inflows}

Figure 9 presents the design hourly rainfall averaged over the 25 rainfall gage stations and the source flows at Makou and Sanshui stations for Syn A and Syn B. The upstream inflows for both Syn A and Syn B are based on the 2017 event, which reached its peak around the 62nd hour into the HEC-HMS simulation for both Makou and Sanshui stations. The design rainfall for Syn A is based on the meteorological condition of the 2018 event but shifted forward by $40 \mathrm{~h}$ so that the peak rainfall is coincident with the peak inflow. According to the IPCC's special report on extreme event risk and disasters [37], the typhoon-induced rainfall is likely to increase due to climate change, and a 20-year return period (RP) annual maximum daily rainfall may shift down to a 5- to 15-year RP by the end of this century in East Asia. Separately, the recent drainage design standards by the Foshan government indicates that the daily rainfall intensity has an average increase of 37\% when going from a 5- to 20-year RP and 13\% when going from a 10- to 20-year RP based on historical records from 1986 to 2015 in Foshan [38]. Thus, a 25\% increase in the total design rainfall is assumed for the Syn B event, i.e., Syn B daily rainfall is $25 \%$ higher than Syn A, with the temporal hourly rainfall distribution and other parameters remaining the same.

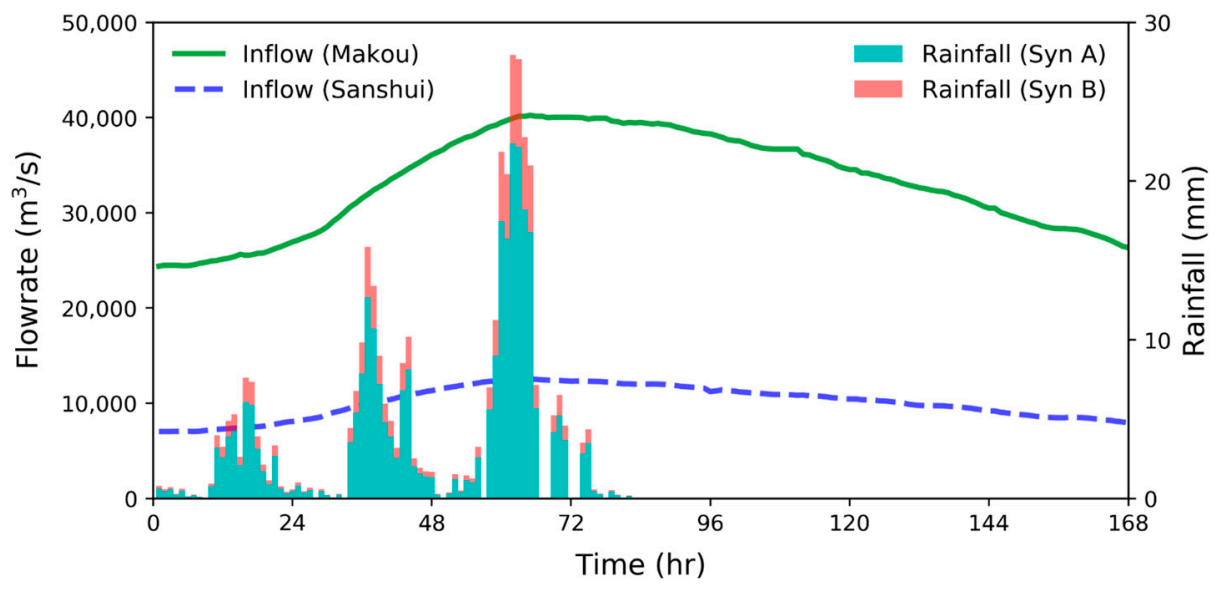

Figure 9. Design river inflows at the source stations (Makou and Sanshui) and the average hourly rainfall from 25 gage stations in the study area for Syn A and B events.

\subsubsection{HEC-HMS Model Results}

The simulated discharges from the HEC-HMS model for the two synthetic events were converted to water levels based on the developed rating curves. Figure 10 shows the calculated water levels together with the warning levels for the same three stations of Ganzhu, Sanduo, and Lanshi as shown in Figure 7. The observed water levels from the 2017 event (dotted line) are included for comparison. The water levels for the synthetic events largely follow the 2017 event, except for the localized peaks 
due to intense rainfall. All three stations have their peak water levels exceeding the corresponding warning levels under both synthetic events.
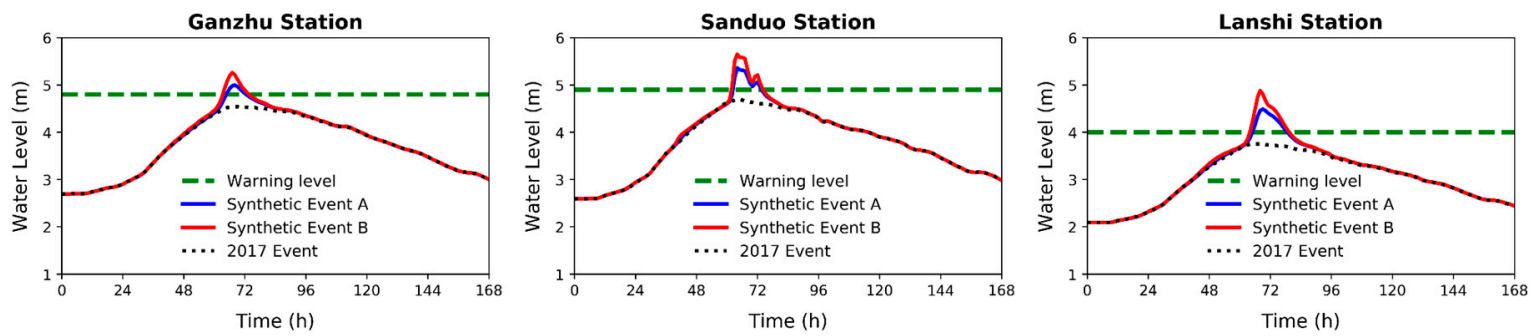

Figure 10. Comparison of the calculated water levels for Syn A and Syn B events along with the 2017 event at Ganzhu, Sanduo and Lanshi stations.

\subsubsection{Potential Inundation Extent and GDP Exposure at Risk}

Figure 11 shows the potential inundation extent of the two synthetic events. The PIC for Syn A has a radius of $8.5 \mathrm{~km}$ while Syn B is $12 \mathrm{~km}$. Table 4 shows the maximum flood depth, total flood area and volume inside the PIC for the two synthetic events. Compared to Syn A, Syn B has a $25 \%$ higher rainfall, which led to an increase in the inundation volume of $74 \%, 78 \%$, and $171 \%$ for Sanduo, Lanshi and Ganzhu PICs, respectively. The maximum flood depths at Sanduo and Ganzhu areas remained similar under both synthetic events, while it increased by $0.1 \mathrm{~m}$ at Lanshi area under Syn B. The total inundated area increases greatly by $82 \%$ for Sanduo area, and similarly, $174 \%$ and $134 \%$ for Lanshi and Ganzhu areas, respectively. Overall, the predicted flooded area for Syn B is $387 \mathrm{~km}^{2}$, a $125 \%$ increase from the flood extent under Syn A $\left(172 \mathrm{~km}^{2}\right)$.
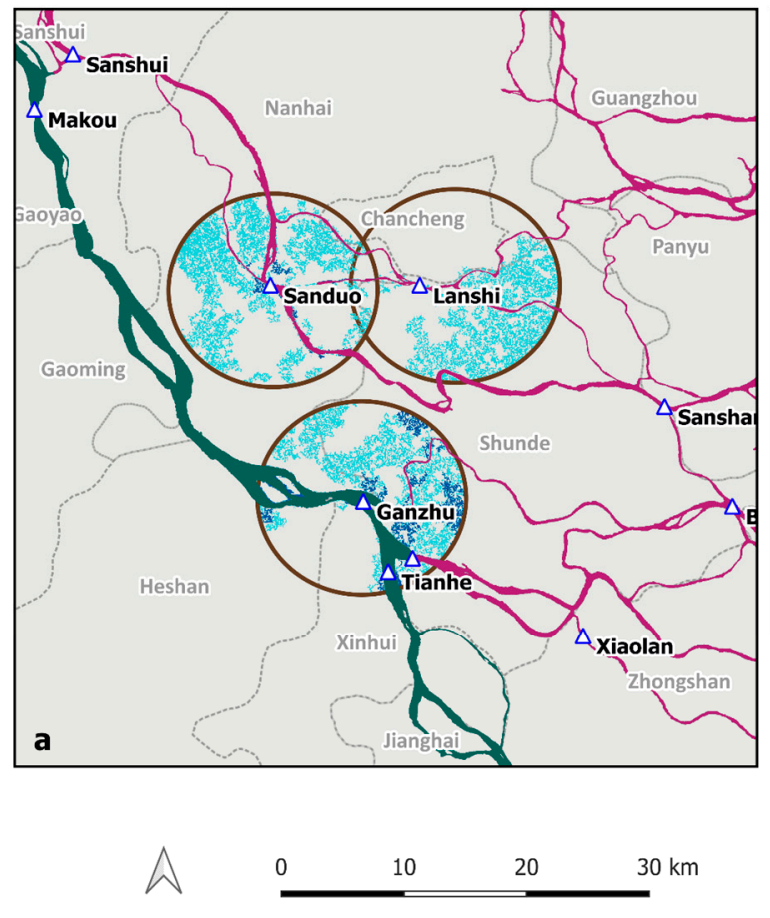
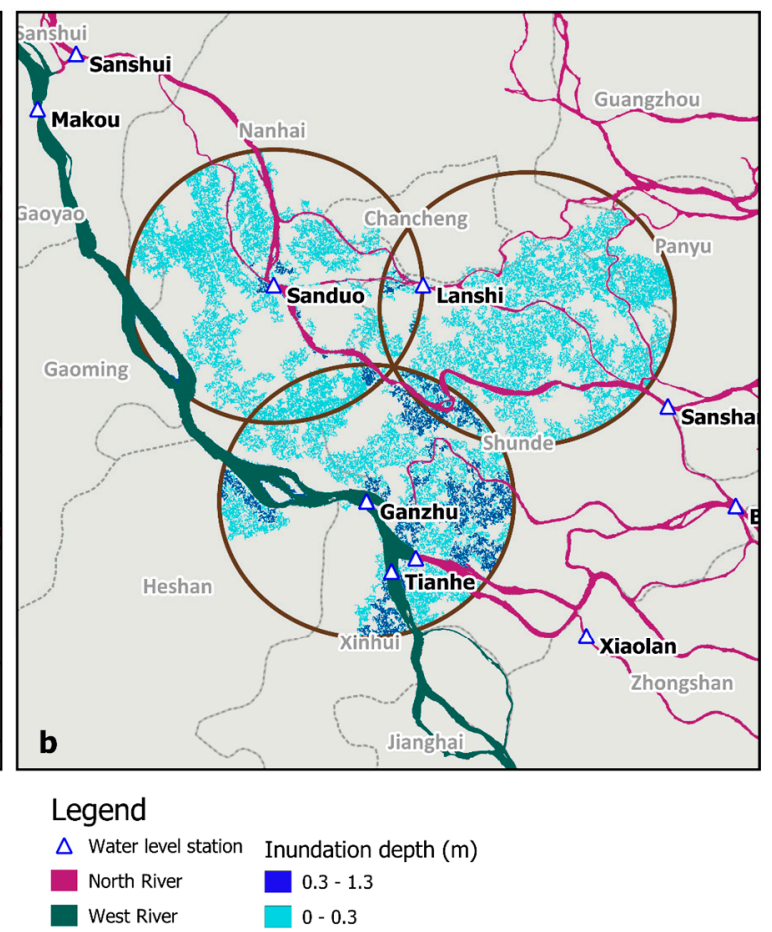

Figure 11. The estimated inundation extent and flood depth under (a) Syn A and (b) Syn B at Sanduo, Lanshi and Ganzhu areas. 
Table 4. Summary of the maximum flood depth, total flood area and volume for the two synthetic events.

\begin{tabular}{ccccc}
\hline Event & Station & $\begin{array}{c}\text { Maximum Flood } \\
\text { Depth } \mathbf{( m )}\end{array}$ & $\begin{array}{c}\text { Total Flood Area } \\
\mathbf{( k m}^{\mathbf{2}} \mathbf{)}\end{array}$ & $\begin{array}{c}\text { Total Overflow } \\
\text { (million, } \mathbf{~ m}^{\mathbf{3}} \mathbf{)}\end{array}$ \\
\hline \multirow{3}{*}{ Syn A } & Sanduo & 1.26 & 65.5 & 19.4 \\
& Lanshi & 0.27 & 46.5 & 12.5 \\
& Ganzhu & 1.23 & 60.0 & 28.4 \\
\hline \multirow{3}{*}{ Syn B } & Sanduo & 1.23 & 119.4 & 33.8 \\
& Lanshi & 0.17 & 127.4 & 22.2 \\
& Ganzhu & 1.25 & 140.2 & 76.9 \\
\hline
\end{tabular}

Since the inundation in the proximity of Sanduo and Ganzhu stations have a flood depth of over $0.3 \mathrm{~m}$, we further assess the GDP exposure at risk for these PICs under both synthetic events. The accumulated GDP at risk for Syn B with two PICs combined is CNY 11.2 billion, this being 2.6 times higher than that of Syn A at CNY 4.3 billion. Table 5 lists the detailed breakdown of the GDP at risk for the two PICs. We can see that by coinciding the extreme rainfall events in 2018 with an approximately 10-20 year RP inflow in the river networks (Syn A), the regional GDP exposure can be subjected to localized flood damage. When the impact from climate change on extreme rainfall events are considered (Syn B), our assessment shows that widespread flooding may be expected with the GDP exposure at risk increased to more than 2.5 times. Thus, both Syn A and B events have a much-increased impact on the regional GDP exposure at risk than the historical events studied, which highlights the regional risk from extreme rainfall events that are likely to be intensified under climate change.

Table 5. Summary of the GDP exposure at risk for the two synthetic events.

\begin{tabular}{cccccc}
\hline \multirow{2}{*}{ Event } & Station & Maximum Flood Depth $\mathbf{( m )}$ & $\begin{array}{c}\text { Total Flooded Area } \\
\mathbf{( k m}^{\mathbf{2}}\end{array}$ & GDP at Risk (billion CNY) \\
\hline \multirow{2}{*}{ Syn A } & Sanduo & 1.26 & 65.5 & 0.6 & 4.3 \\
& Ganzhu & 1.23 & 60.0 & 3.7 & 1.3 \\
\hline \multirow{2}{*}{ Syn B } & Sanduo & 1.23 & 119.4 & 9.9 & 11.2 \\
& Ganzhu & 1.25 & 140.2 & \\
\hline
\end{tabular}

\section{Conclusions}

This paper presented a simple rainfall-runoff model for the Foshan-Zhongshan area in the PRD region using the HEC-HMS model and an empirical procedure for estimating flood inundation. Rainfall and river inflows were inputted into the HEC-HMS model to simulate the discharge along the river networks, and river overflows were used in the empirical determination of flood inundation. This work thus demonstrated a ready methodology for simulating flood events with inundation assessment over a large and complex basin, such as the PRD region, and using only limited publicly accessible data. The rating curves developed in this study would be useful for future PRD studies as such relationships are usually not observed directly.

The developed model was used to perform scenario modeling of high upstream river inflow occurring simultaneously with a high localized rainfall. It further provided a risk assessment of impacts from climate change via an increased daily rainfall of $25 \%$. The results indicate that inundation is largely dependent on upstream river inflow as this drives the river water levels, while local rainfall produces local peaks in these levels. As compared to the 2017 and 2018 events, which only caused localized flooding, the synthetic scenario of large upstream inflow of the 2017 event combined with the large rainfall of the 2018 event resulted in a flood extent of $172 \mathrm{~km}^{2}$ and a total economic exposure at risk of CNY 4.3 billion. The further increased local rainfall scenario had the total flood extent expanded to $387 \mathrm{~km}^{2}$ and the GDP at risk to CNY 11.2 billion. The methodology developed readily allows a 
quantification of flooding potential from local heavy rainfall coincident with large upstream river inflows that are close to their warning levels. It would be of interest to further examine the impact from increased upstream river inflow as arising from climate change on the upstream precipitation.

Author Contributions: Conceptualization, methodology and validation, Q.Z., W.J. and E.Y.M.L.; resources and data curation, Q.Z. and W.J.; software, formal analysis and investigation, Q.Z.; writing-original draft preparation, Q.Z.; writing—review and editing, W.J. and E.Y.M.L.; visualization, Q.Z. and W.J.; supervision, project administration and funding acquisition, E.Y.M.L. All authors have read and agreed to the published version of the manuscript.

Funding: This research received no external funding.

Acknowledgments: Support from the Institute of Catastrophe Risk Management (ICRM), Nanyang Technological University and Axis Reinsurance is gratefully acknowledged.

Conflicts of Interest: The authors declare no conflict of interest.

\section{References}

1. Wei, H.; Hong, W. Innovation Research on Flood Risk Management System. In Innovation Research on Catastrophe Risk Management and Insurance System; Southwestern University of Finance and Economics Press: Chengdu, China, 2012; pp. 157-227.

2. Munich Reinsurance Company. NatCatSERVICE Database. Available online: https://www.munichre.com/ en/solutions/for-industry-clients/natcatservice.html (accessed on 21 October 2019).

3. Jonkman, S.N.; Bočkarjova, M.; Kok, M.; Bernardini, P. Integrated hydrodynamic and economic modelling of flood damage in the Netherlands. Ecol. Econ. 2008, 66, 77-90. [CrossRef]

4. Skakun, S.; Kussul, N.; Shelestov, A.; Kussul, O. Flood hazard and flood risk assessment using a time series of satellite images: A case study in Namibia. Risk Anal. 2014, 34, 1521-1537. [CrossRef] [PubMed]

5. Pellicani, R.; Parisi, A.; Iemmolo, G.; Apollonio, C. Economic risk evaluation in urban flooding and instability-prone areas: The case study of San Giovanni Rotondo (Southern Italy). Geosciences 2018, 8, 112. [CrossRef]

6. Hallegatte, S. An adaptive regional input-output model and its application to the assessment of the economic cost of Katrina. Risk Anal. 2008, 28, 779-799. [CrossRef]

7. De Bono, A.; Mora, M.G. A global exposure model for disaster risk assessment. Int. J. Disaster Risk Reduct. 2014, 10, 442-451. [CrossRef]

8. Wu, J.; Wang, C.; He, X.; Wang, X.; Li, N. Spatiotemporal changes in both asset value and GDP associated with seismic exposure in China in the context of rapid economic growth from 1990 to 2010. Environ. Res. Lett 2017, 12, 034002. [CrossRef]

9. Revi, A.; Satterthwaite, D.; Aragón-Durand, F.; Corfee-Morlot, J.; Kiunsi, R.B.R.; Pelling, M.; Roberts, D.; Solecki, W. Urban areas. In Climate Change 2014: Impacts, Adaptation, and Vulnerability. Part A: Global and Sectoral Aspects. Contribution of Working Group II to the Fifth Assessment Report of the Intergovernmental Panel on Climate Change; Cambridge University Press: Cambridge, UK; New York, NY, USA, 2014; pp. 535-612.

10. Zhao, R. The Xinanjiang model applied in China. J. Hydrol. 1992, 135, 371-381. [CrossRef]

11. Li, Z.; Liu, P.; Zhang, W.; Chen, X.; Deng, C. Comparative Study on the Performance of SWAT and Xin'anjiang Models in Xunhe Basin. J. Water Resour. Res. 2014, 3, 307-314. [CrossRef]

12. Hao, F.; Sun, M.; Geng, X.; Huang, W.; Ouyang, W. Coupling the Xinanjiang Model with Geomorphologic Instantaneous Unit Hydrograph for Flood Forecasting in Northeast China. Int. Soil Water Conserv. Res. 2015, 3, 66-76. [CrossRef]

13. Yang, S.T.; Dong, G.T.; Zheng, D.H.; Xiao, H.L.; Gao, Y.F.; Lang, Y. Coupling Xinanjiang model and SWAT to simulate agricultural non-point source pollution in Songtao watershed of Hainan, China. Ecol. Model. 2011, 222, 3701-3717. [CrossRef]

14. Wu, Y.; Chen, J. Modeling of soil erosion and sediment transport in the East River Basin in southern China. Sci. Total Environ. 2012, 441, 159-168. [CrossRef] [PubMed]

15. 15. Zhang, J.; Ni, S.; Wu, W.; Huang, X.; Jiang, H.; Li, Q.; Wang, J.; Wu, G.; Zorn, C.; Yu, C. Evaluating the effectiveness of the pollutant discharge permit program in China: A case study of the Nenjiang River Basin. J. Environ. Manag. 2019, 251, 109501. [CrossRef] [PubMed] 
16. Peng, D.; Zhijia, L.; Fan, X. Application of TOPMODEL in Buliu River Catchment, Pearl River Basin and Comparison with Xin'anjiang Model. J. Lake Sci. 2009, 21, 441-444. [CrossRef]

17. Li, W.J.; Lin, K.R.; Zhao, T.T.G.; Lan, T.; Chen, X.H.; Du, H.W.; Chen, H.Y. Risk assessment and sensitivity analysis of flash floods in ungauged basins using coupled hydrologic and hydrodynamic models. J. Hydrol. 2019, 572, 108-120. [CrossRef]

18. Chen, Y.; Xu, Y.P.; Yin, Y.X. Impacts of land use change scenarios on storm-runoff generation in Xitiaoxi basin, China. Quatern. Int. 2009, 208, 121-128. [CrossRef]

19. Grimaldi, S.; Petroselli, A.; Arcangeletti, E.; Nardi, F. Flood mapping in ungauged basins using fully continuous hydrologic-hydraulic modeling. J. Hydrol. 2013, 487, 39-47. [CrossRef]

20. Oleyiblo, J.O.; Li, Z.J. Application of HEC-HMS for Flood Forecasting in Misai and Wan'an Catchments in China. Water Sci. Eng. 2010, 3, 14-22. [CrossRef]

21. Du, J.K.; Qian, L.; Rui, H.Y.; Zuo, T.H.; Zheng, D.P.; Xu, Y.P.; Xu, C.-Y. Assessing the effects of urbanization on annual runoff and flood events using an integrated hydrological modeling system for Qinhuai River basin, China. J. Hydrol. 2012, 464-465, 127-139. [CrossRef]

22. Zhang, H.L.; Wang, Y.J.; Wang, Y.Q.; Li, D.X.; Wang, X.K. Quantitative comparison of semi- and fully-distributed hydrologic models in simulating flood hydrographs on a mountain watershed in Southwest China. J. Hydrodyn. 2013, 25, 877-885. [CrossRef]

23. Guangdong Bureau of Statistics. Guangdong Statistical Yearbook 2017. Available online: http://stats.gd.gov. cn/gdtjnj/index.html (accessed on 25 April 2019).

24. US Army Corps of Engineers. Hydrologic Modeling System HEC-HMS Technical Reference Manual, March 2000. Available online: https://www.hec.usace.army.mil/software/hec-hms/documentation/HEC-HMS_ Technical\%20Reference\%20Manual_(CPD-74B).pdf (accessed on 1 April 2020).

25. Urban Hydrology for Small Watersheds; Technical Release 55; USDA: Washington, DC, USA, 1986.

26. Liu, J. A study on diversion points and distribution feature on the Pearl River Delta river network. Pearl River 2015, 1, 90-95.

27. Wang, J.; Yu, G.; Chen, Z. Simulation on tidal flow rate at sea area of Lingding channel at the estuary of Pearl River. Acta Oceanol. Sin. 1992, 14, 26-34.

28. Long, J.; Li, S. Application of the finite element combined solution to the Zhujiang Estuary hydrodynamic research. Acta Oceanol. Sin. 2007, 29, 10-14.

29. Wei, X.; Zhu, Y.; Zhang, W.; Sun, S. Study on salt flux value simulation during dry season at the estuary of Pearl River. Trop. Geogr. 2012, 32, 216-222. [CrossRef]

30. Guangdong Provincial Local Records Database. Pearl River Delta General Introduction. Available online: http://www.gd-info.gov.cn/books/10651/932.html (accessed on 28 July 2017).

31. Delkash, M.; Bakhshayesh, B.E. An examination of rectangular side weir discharge coefficient equations under subcritical condition. Int. J. Hydraul. Eng. 2014, 24-34. [CrossRef]

32. Singh, R.; Manivannan, D.; Satyanarayana, T. Discharge coefficient of rectangular side weirs. J. Irrig. Drain. Eng. 1994, 120, 814-819. [CrossRef]

33. Huang, Y.; Jiang, D.; Fu, J. 1 km grid GDP data of China (2005, 2010). Acta Geogr. Sin. 2014, 69, 40-143.

34. Department of Water Resources of Guangdong Province. Public flood information of the 20-year flood in the West River. Available online: http://zwgk.gd.gov.cn/006941135/201707/t20170706_712531.html (accessed on 31 July 2018).

35. Lin, Q.W. Journalist Captured Pictures of the Flood Impact on Zhongshan City. ZSBTC. Available online: http://zsbtv.com.cn/a/ats/content_84733.shtml (accessed on 16 January 2018).

36. Wu, J.; Lu, J.; Liu, X.P.; Hou, Y.X.; Yang, Q.; Wen, J.Z.; Guo, C.Y.; Hu, H.J. Flood Peak Coming to Zhongshan Yinggezui, Approaching Warning level. Southern Metropolis Daily. Available online: http://finance.ifeng.com/a/ 20170706/15514783_0.shtml (accessed on 16 January 2018). 
37. Intergovernmental Panel on Climate Change (IPCC). Managing the Risks of Extreme Events and Disasters to Advance Climate Change Adaptation. In A Special Report of Working Groups I and II of the Intergovernmental Panel on Climate Change; Cambridge University Press: Cambridge, UK; New York, NY, USA, 2012; 582p.

38. Foshan Municipal Administration of State Land, Urban and Rural Planning. Planning Guidelines of Sponge City for the Foshan City. 2016. Available online: http://fszrzy.foshan.gov.cn/attachment/0/47/47656/762585.pdf (accessed on 5 March 2018).

(C) 2020 by the authors. Licensee MDPI, Basel, Switzerland. This article is an open access article distributed under the terms and conditions of the Creative Commons Attribution (CC BY) license (http://creativecommons.org/licenses/by/4.0/). 